\title{
ACONDICIONAMENTO E ROTULAGEM DO CHÁ DE CAPIM-LIMÃO (Cymbo- pogon citratus (D.C.) Stapf) COMERCIALIZADO PELO SEGMENTO SUPERMERCADO NA CIDADE DE CURITIBA ${ }^{1}$
}

\section{PACKAGING AND LABELLING OF LEMON GRASS TEA (Cymbopogon citratus (D.C.) Stapf) COMMERCIALIZED BY SUPERMARKETS IN CURITIBA CITY}

\author{
ELIANE CARNEIRO GOMES ${ }^{2}$, RAQUEL R.B.NEGRELLE ${ }^{3}$,NEUSA G.A. RÜCKER ${ }^{4}$
}

\author{
RECEBIDO: JUNHO/2005 ACEITO: AGOSTO/2005 \\ ${ }^{1}$ Parte da tese de doutorado em Agronomia pela UFPR, do primeiro autor. \\ ${ }^{2}$ Doutora em Agronomia; Professora do Departamento de Saúde Comunitária; Universidade Federal do Paraná. \\ R. Padre Camargo,280, $7^{\circ}$ andar, Alto da Glória, 80060-240, Curitiba, PR..E--mail: gomes@ufpr.br. Autor para \\ correspondência. \\ ${ }^{3}$ Doutora em Ecologia; Professora do Departamento de Botânica, UFPR. E-mail: negrelle@ufpr.br). \\ ${ }^{4}$ Pesquisadora Científica do Departamento de Economia Rural-Secretaria de Estado da Agricultura e do \\ Abastecimento do Paraná. E-mail: neusagar@pr.gov.br.
}

\section{RESUMO}

Apresentam-se informações sobre acondicionamento e rotulagem das marcas de chá de capim-

Limão (Cymbopogon citratus (D.C.) Stapf), comercializadas pelo segmento supermercado na cidade de Curitiba. Tais informações foram obtidas, no período de agosto a outubro de 2001, por meio de pesquisa de campo, observação participante e documentação legal. No total, foram identificadas e analisadas 19 marcas de chá de capim-limão, sendo $47,36 \%$ de procedência paranaense. Constatou-se que $68,4 \%$ das marcas estavam acondicionadas em embalagens secundárias ou terciárias e 35,6\% apresentavam-se em embalagens primárias, ou seja, a embalagem em contato direto com o alimento. Quanto à rotulagem, a maioria das marcas analisadas apresentava-se adequada à legislação vigente no que concerne à quase totalidade dos parâmetros considerados. A incorreção mais freqüente foi com relação à denominação de venda. Registrou-se ausência de rotulagem nutricional em cerca de dois terços das marcas analisadas, na época da pesquisa. Constatou-se por meio de análise comprobatória posterior, a adequação de cerca de $56 \%$ destas marcas, quanto à rotulagem correta da embalagem.

Palavras-chave: alimento, qualidade, embalagem.

\section{ABSTRACT}

Introduce informations about packaging and labelling of lemon grass, Cymbopogon citratus (D.C.) Stapf tea trademarks commercialized by supermarkets in Curitiba city. These informations were obtained between august and december of 2001, through field research, participative observation and legal documents. On totality, were identified and analysed 19 trademarks of lemon grass tea, $47,36 \%$ of them were from Paraná State. It was verified that $68,4 \%$ of trademarks were packed in secondary or terciary packages and $35,6 \%$ showed primary packages, as the package was in direct contact with food. About the labelling, the majority of trademarks analysed were suitable with the actual legislation in almost totality of considerated questions. The more frequent mistake was about the sale designation. It was registered the lack of nutritional information in two third parts of avaliated trademarks, by the time of the research. Later analyses allowed to evidence the adequation of near $56 \%$ of this trademarks about that question.

Key-words: food, quality, labelling.

\section{INTRODUÇÃO}

Cymbopogon citratus (D.C.) Stapf (Poaceae) é espécie herbácea perene, de porte alto, originária da İndia e cultivada em vários países, inclusive no Brasil (AKISUE 
Et al.,1996). Chamada popularmente de capim-limão, capim-santo, capim-cidrão e erva-cidreira, tem emprego popular, uso e aplicação industrial como fitoterápico entre outros. O óleo essencial presente nas folhas desta espécie, contém de 30 a mais de $90 \%$ de citral, o qual é a mistura dos aldeídos geranial e neral (OLIVEIROS-BELARDO e AUREUS, 1979; RABHA et al., 1979; TORRES, 1993). Também, possui outros aldeídos como citronelal, isovaleraldeído e decilaldeído. Entre suas propriedades farmacológicas, destacam-se: efeito antiespasmódico do tecido uterino e intestinal, analgésico, antibacteriano (TESKE e TRENTINI, 1997). É tida também como ansiolítica e digestiva, apesar de que estas propriedades não foram confirmadas em testes farmacológicos "in vivo", realizados em animais e humanos (FARMACOLOGIA, 1985; LEITE et al., 1986; SILVAet al.,1991).

Esta planta, atualmente, encontra-se entre os 10 componentes do grupo de produtos especiais de maior importância sócio-econômico e financeira para as comunidades agrícolas paranaenses. Segundo dados da Secretaria de Estado da Agricultura e do Abastecimento (PARANÁ, 2001), a produção agrícola de capim-limão, safra 1999/2000, foi de 280,25 toneladas, a área ocupada foi de 26,2 hectares e participou com aproximadamente 311 mil reais no Valor Bruto da Produção Agrícola (VBP) no Estado do Paraná. Para a safra 2000/2001 (PARANÁ, 2002), registrou-se um incremento na produção de $14 \%$, representado por quase 320 toneladas, em área superior a 23 hectares, contribuindo para o VBP em mais de 650 mil reais ${ }^{1}$.

Dentre as diversas formas de comercialização do capim-limão, salienta-se aquela utilizada para fins alimentícios, na forma de chá ${ }^{2}$ Curitiba, enquanto capital do Estado, destaca-se como centro de industrialização e comercialização de grande parte da produção de chá de capim-limão do Estado (PARANÁ, 2003). Das 9 marcas de chá de capim-limão produzidas no Estado do Paraná, 7 são industrializadas e comercializadas em Curitiba e Região Metropolitana .

Os produtos comercializados como alimento devem ser submetidos a constante controle sanitário, visando a saúde da população. Para contribuir neste sentido, a Agência Nacional de Vigilância Sanitária (ANVISA) do Ministério da Saúde, estabelece os padrões de identidade e qualidade característicos para cada produto alimentício (Brasil,1993, 1998a). Adicionalmente, formulou e divulgou em 20 de setembro de 2002, a Resolução da Diretoria Colegiada (RDC) $n^{\circ} 259$, que padroniza definições e estabelece critérios sobre a rotulagem de alimentos embalados, assim como o rol de informações de caráter obrigatório a serem incorporadas nos rótulos (Brasil, 2002b), em substituição à Portaria n 42 de 14 de janeiro de 1998 (Brasil, 1998b). Segundo a RDC n²59, as informações de caráter obrigatório na rotulagem de alimentos embalados são: denominação de venda do alimento, lista de ingredientes, conteúdos líquidos, identificação da origem, nome ou razão social e endereço do importador, no caso de alimentos importados, identificação do lote, prazo de validade e instruções sobre o preparo e uso do alimento, quando necessário. Também, esta resolução estabelece que os alimentos embalados não devem apresentar em seu

${ }^{1}$ Dados preliminares da SEAB/PR (PARANÁ, 2004), apresentam uma estimativa para a produção agrícola de capim-limão, última safra 2002/2003, de 987,92 toneladas numa área de 24,5 hectares. Isto configura a triplicação da produção em relação a safra 1999/2000,. Infere-se que tal situaçào evidencia que trabalhos voltados a esta cultura agrícola contribuem de alguma forma para sua melhoria em termos de produção e qualificação.

2 No Brasil, o Ministério da Saúde define "chás" como produtos constituídos de partes vegetais inteiras, fragmentadas ou moídas, obtidas por processos tecnológicos adequados a cada espécies, utilizados exclusivamente na preparação de bebidas alimentícias por infusão ou decocção em água potável, não podendo ter finalidades famacoterapêuticas, segundo a Portaria nº. 519 de 26/06/98 (BRASIL, 1998a). 
Rótulo "efeitos ou propriedades que não possuam ou indicação que o alimento possua propriedades medicinais ou terapêuticas".

Além da RDC n²59, a ANVISA divulgou também as RDC n³ 39 e 40 em 21 de março de 2001, as quais aprovam aspectos sobre a rotulagem nutricional obrigatória de alimentos e bebidas embalados (BRASIL, 2001 b, c). Desde então, todo e qualquer alimento embalado deve estar de acordo com as especificações ali listadas, de modo a garantir que o consumidor tenha plena informação a que tem direito, assim como que as unidades de controle sanitário tenham mais uma ferramenta de apoio na execução de seu trabalho.

Desta forma, considerando-se a importância do capim-limão no contexto agrícola do Estado do Paraná e o volume comercializado deste chá na Região Metropolitana de Curitiba, buscou-se identificar as marcas de chá de capim-limão comercializadas em Curitiba, avaliando-se o acondicionamento e a rotulagem, tendo por referência as normas citadas nas Resoluções da ANVISA, de modo a subsidiar o controle de qualidade deste produto. Também, observou-se a presença ou a ausência de registro no rótulo do uso de irradiação ou de outro processo análogo. $A R D C n^{\circ} 21$ de 26 de janeiro de 2001 (BRASIL, 2001a) regulamenta o uso da irradiação em alimentos e a define como um processo físico de tratamento que consiste em submeter o alimento a doses controladas de radiação ionizante, com finalidade sanitária, fitossanitária e/ou tecnológica. Porém, este processo não é capaz de ser aplicado em qualquer situação e o tratamento requer técnicas especializadas e equipamento sofisticado (BENDER,1982; RIEDEL,1992). Também, se utilizado este processo, tal ação deve estar explicitada no rótulo do produto comercializado.

A comercialização de produtos alimentícios no Brasil é dominada pelo segmento supermercado, cuja participação é em torno de $75 \%$ (APRAS, 2000). Neste percentual estão incluídas as vendas dos chás de plantas medicinais, como o de capimlimão. Segundo pesquisa da Associação Brasileira de Propaganda, publicada em APRAS (1999) e realizada em várias cidades brasileiras englobando 12 Estados, o consumidor de Curitiba realiza $95 \%$ de suas compras em supermercados, versus $74 \%$ da média nacional. Por esta razão, o segmento "supermercado", englobando hipermercados e supermercados, foi utilizado como delimitação amostral no âmbito deste trabalho.

\section{MATERIALE MÉTODOS}

\section{1 ÁREAESTUDADA}

Curitiba ( $25^{\circ} 25^{\prime}$ Sul; $49^{\circ} 16^{\prime}$ Oeste), capital do Estado do Paraná,situa-se ao sul do Brasil, Figura 1. Possui 1.6 milhão de habitantes distribuídos desigualmente em 75 bairros, os quais estão organizados em 8 Administrações Regionais (AR) (CURITIBA,2001a,b). 
FIGURA 1 - LOCALIZAÇÃO DA ÁREA DE ESTUDO, CURITIBA, PARANÁ, BRASIL.

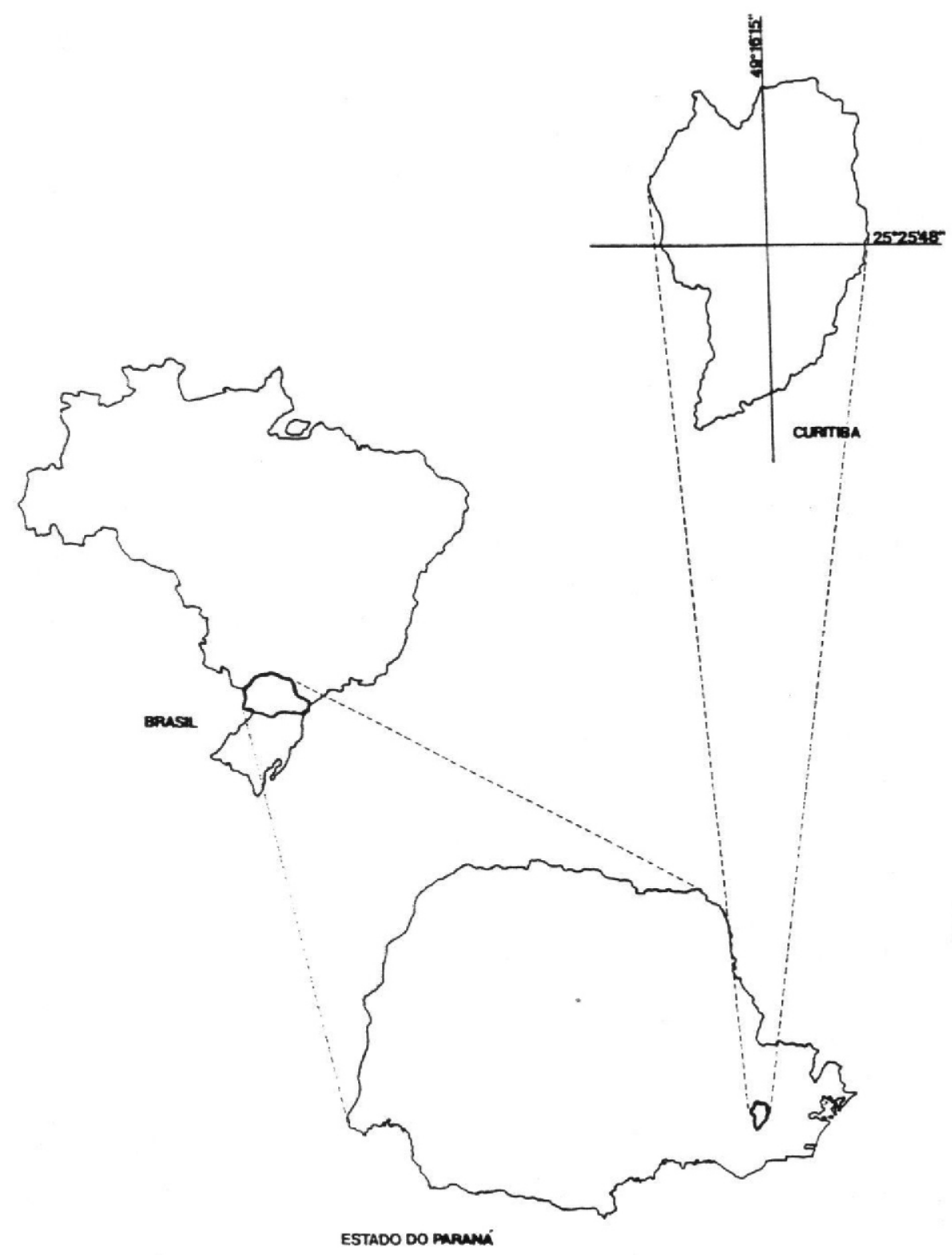

A delimitação geográfica da área de estudo, figura 2, abrangeu os bairros mais populosos situados nas oito AR de Curitiba. 


\section{FIGURA 2 - LOCALIZAÇÃO DAS 8 ADMINISTRAÇÕES REGIONAIS(AR) DE CURITIBA (PR) COM RESPECTIVOS PERCENTUAIS POPULACIONAIS.}

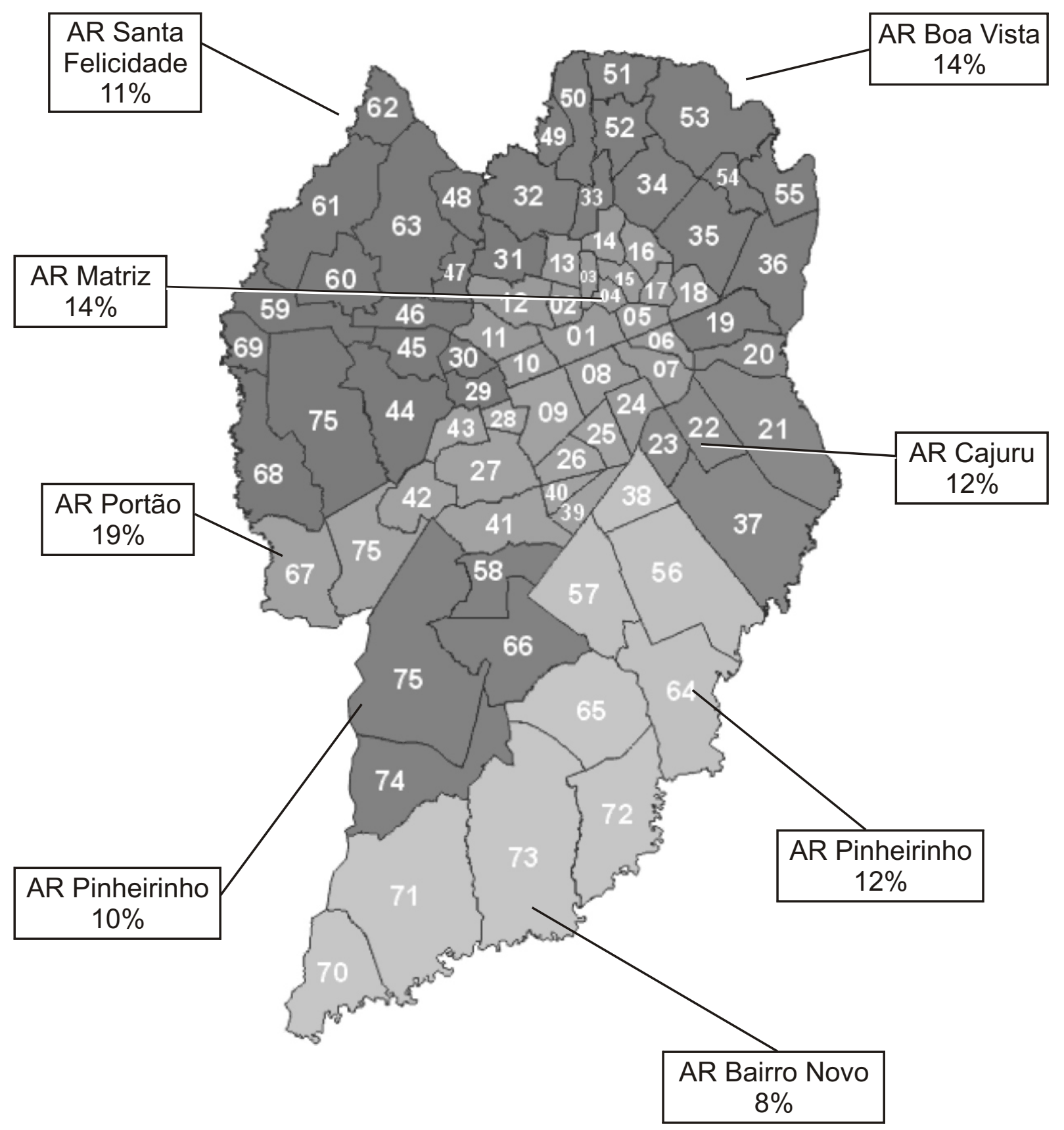

FONTE: CURITIBA/IPPUC, 2001b. Elaboração das autoras.

NOTA: Os números anotados no mapa correspondem aos bairros que pertencem as ar, listados na tabela 1. 


\section{TABELA 1 - ADMINISTRAÇÕES REGIONAIS (AR) DE CURITIBA E RESPECTIVOS BAIRROS, 2001.}

\begin{tabular}{|c|c|}
\hline AR & BAIRROS COM RESPECTIVAS NUMERAÇÖES \\
\hline Bairro Novo & 71.Campo de Santana; 70. Caximba; 72. Ganchinho; 65. Sítio Cercado; 73. Umbará \\
\hline Boa Vista & $\begin{array}{l}\text { 50.Abranches; 55. Atuba; 35. Bacaheri; 36. Bairro Novo; 52. Barreirinha; 34. Boa } \\
\text { Vista; 51. Cachoeira; 32. Pilarzinho; 53. Santa Cândida;33. São Lourenço; } 49 . \\
\text { Taboão; 19. Tarumã; 54. Tingüi }\end{array}$ \\
\hline Boqueirão & 64. Alto Boqueirão; 56 . Boqueirão; 38. Hauer; 57 . Xaxim \\
\hline Cajuru & $\begin{array}{l}\text { 21. Cajuru; 20. Capão da Imbuia; 23. Gurabirotuba; 22. Jardim das Américas; } 37 . \\
\text { Uberaba }\end{array}$ \\
\hline Matriz & $\begin{array}{l}\text { 14. Ahú; 04. Alto da Glória; } 05 \text {. Alto da Rua XV; 10. Batel; 11. Bigorrilho; 13. Bom } \\
\text { Retiro; 16. Cabral; 01. Centro; 03. Centro Cívico; 17. Hugo Lange; 07. Jardim } \\
\text { Botânico; 18. Jardim Social; } 15 \text {. Juvevê; } 12 \text {. Mercês; } 24 \text {. Prado Velho, 08. Rebouças; } \\
\text { 02. São Francisco }\end{array}$ \\
\hline Pinheirinho & 58. Capão Raso; 75. Cidade Industrial; 66 . Pinheirinho; 74. Tatuquara \\
\hline Portão & $\begin{array}{l}\text { 09. Agua Verde; } 75 \text {. Cidade Industrial; 39. Fanny; 42. Fazendinha; 26. Guairá; } 40 . \\
\text { Lindóia; } 41 \text {. Novo Mundo; 25. Parolin; 27. Portão; 43. Santa Quitéria; } 67 \text {. São Miguel; } \\
\text { 28. Vila Isabel }\end{array}$ \\
\hline $\begin{array}{l}\text { Santa } \\
\text { Felicicade }\end{array}$ & $\begin{array}{l}\text { 68. Augusta; 61. Butiatuvinha; 30. Campina do Siqueira; 44. Campo Comprido; } 47 . \\
\text { Cascatinha; 75. Cidade Industrial; } 62 \text {. Lamenha Pequena; 45. Mossunguê; } 59 . \\
\text { Orleans; 69. Riviera; 63. Santa Felicidade; } 46 \text {. Santo Inácio; } 60 \text {. São Braz; 48. São } \\
\text { João; 29. Seminário }\end{array}$ \\
\hline
\end{tabular}

FONTE: IPPUC, 2001. Adaptação das autoras.

\subsection{SELEÇÃO DOS ESTABELECIMENTOS}

Segundo documentação da Associação Paranaense de Supermercados (APRAS, 2001), o segmento supermercado engloba 153 estabelecimentos distribuídos em 50 bairros de Curitiba.

No âmbito deste trabalho, para a análise das marcas de chá de capim-limão, foram selecionados 30 estabelecimentos localizados nas 8 AR (Tabela 2), os quais se enquadravam em pelo menos um dos seguintes critérios:

1- Comercializar o produto agrícola capim-limão, independente da marca, mas preferencialmente de origem do Estado do Paraná;

2- Estar localizado em bairro bem classificado em termos de população na AR (até terceiro ou quarto lugar) e possuir ampla área física, relativamente aos demais estabelecimentos do bairro;

3- Estar bem classificado no ranking de maior faturamento no ano de 2000 , segundo a Associação Brasileira de Supermercados (ABRAS, 2000). 


\section{TABELA 2 - CRITÉRIOS DE SELEÇÃO DOS ESTABELECIMENTOS DO SEGMENTO SUPERMERCADO SELECIONADOS PORAR E BAIRROS DE CURITIBA}

\begin{tabular}{|c|c|c|c|}
\hline$A R^{*}$ & $\operatorname{BAIRRO}(\mathrm{S})^{\star}$ & ESTABELECIMENTO(S) & CRITÉRIO (S) \\
\hline \multirow[t]{4}{*}{ 1-Portão } & CIC-Centro & Lembrasul Supermercados & 2,3 . \\
\hline & Água Verde & $\begin{array}{l}\text { Supermercado Festival; } \\
\text { Extra Kennedy } \\
\text { Supermercados Pão de Açúcar }\end{array}$ & $\begin{array}{c}1 \\
2,3 \\
3\end{array}$ \\
\hline & Portão & Hipermercado Big & $1,2,3$ \\
\hline & Parolin & Carrefour Parolin & 3 \\
\hline \multirow[t]{2}{*}{ 2-Boa Vista } & Bairro Alto & $\begin{array}{l}\text { Benato Supermercados } \\
\text { Supermercado Cilla }\end{array}$ & 2 \\
\hline & Boa Vista & Hipermercado Big & $1,2,3$. \\
\hline \multirow[t]{9}{*}{ 3-Matriz } & Centro & Mercadorama & $1,2,3$ \\
\hline & Cristo Rei & $\begin{array}{l}\text { Supermercados Pão de Açúcar } \\
\text { Extra }\end{array}$ & 3 \\
\hline & Bigorrilho & Carrefour Champangnat & 3 \\
\hline & Jardim Social & Supermercados Pão de Açúcar & 3 \\
\hline & Alto da Rua XV & Supermercado Festival & 1 \\
\hline & Batel & Lembrasul Supermercados & 3 \\
\hline & Juvevê & Mercadorama & $1,2,3$ \\
\hline & Mercês & Supermercado Festival & 1 \\
\hline & Jardim Botânico & Hipermercado Big & 1,3 \\
\hline \multirow[t]{3}{*}{ 4-Boqueirão } & Boqueirão & Supermercados Jacomar & 2 \\
\hline & Xaxim & Hipermercado Big & $1,2,3$ \\
\hline & Vila Hauer & Supermercado Superpão & 1,3 \\
\hline \multirow[t]{2}{*}{ 5-Cajuru } & Cajuru & Supermercado Festival; & 1,2 \\
\hline & Jardim das Américas & Wal-mart Brasil Ltda & $1,2,3$ \\
\hline \multirow[t]{3}{*}{ 6-Santa Felicidade } & Santa Felicidade & Hipermercado Big & $1,2,3$. \\
\hline & São Braz & Condor Super Center & 2,3 \\
\hline & Seminário & Mercadorama & $1,2,3$ \\
\hline 7-Pinheirinho & Pinheirinho & Condor Super Center & 2,3 \\
\hline 8- Bairro Novo & Sítio Cercado & $\begin{array}{l}\text { Stall Supermercados } \\
\text { Videira Supermercados }\end{array}$ & $\frac{2}{2}$ \\
\hline TOTAL & 25 & 30 & \\
\hline
\end{tabular}

FONTE: Pesquisa de campo, 2001.

NOTA: *AR e bairros apresentados em ordem decrescente de população.

** A descrição dos critérios antecede a esta tabela.

\subsection{OBTENÇÃO E ANÁLISE DOS DADOS}

Durante o levantamento de dados referente as marcas comercializadas do produto chá de capim-limão disponibilizado nos supermercados selecionados, no período de agosto a outubro de 2001, priorizou-se nas seções de mercearia e hortifrutigranjeiros as gôndolas de chás e condimentos tanto dos chamados produtos orgânicos quanto dos convencionais. Para cada uma das marcas de chá de capimlimão identificada, foram obtidas informações in loco sobre tipos de acondicionamento, rotulagem e utilização de irradiação ou processo análogo. Adicionalmente, foram realizadas entrevistas com técnicos responsáveis pelas marcas identificadas, com vistas a conferência da aplicação ou não de processo de irradiação nos produtos. 
A RDC n 21 (BRASIL, 2001a) referenciou esta avaliação relativa ao uso da irradiação em alimentos. A avaliação dos tipos de acondicionamento e a rotulagem foi realizada tendo por base as definições, princípios e determinações da Portaria $n^{\circ} 42$ (BRASIL,1998b) e das Resoluções-RDC n. 259 (BRASIL, 2002b) e n 39 e 40 (BRASIL, 2001b e 2001c), da Agência Nacional de Vigilância Sanitária do Ministério da Saúde.

A rotulagem nutricional do chá de capim-limão também foi analisada segundo as já citadas $R D C n^{\circ} .39$ e $n^{\circ} .40$. ARDC $n^{\circ} 39$ estabelece os valores de referência (VR) de alimentos embalados. Assim, para os chás em saquinhos, o VR equivale ao volume da infusão pronta para o consumo. A medida caseira é a xícara, a quantidade média por medida caseira é de $200 \mathrm{ml}$ e a forma de apresentação da medida caseira no rótulo é uma xícara de chá. A RDC 40 estabelece a declaração obrigatória no rótulo de valor calórico, seguida, dos componentes, na seguinte ordem: carboidratos, proteínas, gorduras totais e sódio, cujas unidades são para os três primeiros o grama e para o último, o miligrama. O valor calórico é declarado em Kcal. A informação nutricional deve ser apresentada em um mesmo local no rótulo e estruturada em forma de tabela. Salienta-se que a análise da rotulagem nutricional foi efetuada em apenas 9 dentre as 19 marcas identificadas, considerando a fase de adequação à nova legislação. O prazo legal para cumprimento das citadas resoluções foi estabelecido para 20 de março de 2003 (BRASIL, 2002a; 2003a). Desta forma, 9 marcas foram escolhidas aleatoriamente e analisadas no sentido de se obter um referencial da situação na época da realização deste trabalho.

No que concerne à denominação de venda do alimento (ou nome específico), foi utilizada a Portaria da ANVISA n 519 (BRASIL, 1998a), que estabelece o padrão de identidade e qualidade de chás, além das citadas RDC n²59 e Portaria nº42.

\section{RESULTADOS E DISCUSSÃO}

\subsection{ACONDICIONAMENTO E ROTULAGEM OBRIGATÓRIA DO CHÁ ENQUANTOALIMENTO}

\subsubsection{IDENTIFICAÇÃO DAORIGEM DAS MARCAS}

Nos 30 estabelecimentos pesquisados foi registrada a comercialização de chá de capim-limão, identificando-se um número variável de marcas, num total de 19 (Tabela 3). As marcas mais freqüentemente encontradas nestes estabelecimentos $(88,23 \%)$ foram Leão Júnior e Real, produzidas no Estado do Paraná, figura 3. As outras marcas produzidas no Estado do Paraná, como: Carrefour, Great Vallue, Poliervas, Celeiro do Brasil, Chamel eram comercializadas com exclusividade pelos estabelecimentos seguintes: Carrefour, Wal-Mart, Condor, Superpão e Festival, respectivamente. As marcas Produtos da Roça e Terra Ervas estavam disponíveis na rede SONAE (BIG e Mercadorama). 
TABELA 3 - MARCAS DE CHÁ DE CAPIM-LIMÃO DISPONIBILIZADAS NOS ESTA BELECIMENTOS DO SEGMENTO SUPERMERCADO, EM CURITIBAAGO-OUT. 2001.

\begin{tabular}{|c|c|c|}
\hline $\begin{array}{c}\text { ESTABELECIMENTO/NÚMERO } \\
\text { DE LOJAS VISITADAS }\end{array}$ & MARCAS COMERCIALIZADAS & $\begin{array}{c}\text { TOTAL DE } \\
\text { MARCAS } \\
\text { COMERCIALI } \\
\text { ZADAS }\end{array}$ \\
\hline Wal-Mart Brasil Ltda/1 & $\begin{array}{l}\text { Leão, Real, Great Vallue, Oetker, } \\
\text { LinTea, Chinatown, Castellari, } \\
\text { Api.Chá. }\end{array}$ & 8 \\
\hline Mercadorama/3 & $\begin{array}{l}\text { Leão, Real, Mercadorama, Terra } \\
\text { Ervas, Produtos da Roça, Oetker, Lin } \\
\text { Tea, Api.Chá. }\end{array}$ & 8 \\
\hline Hipermercado BIG/5 & $\begin{array}{l}\text { Leão, BIG, Terra Ervas, Produtos da } \\
\text { Roça, Oetker, Lin Tea, Api.Chá. }\end{array}$ & 7 \\
\hline Carrefour/2 & $\begin{array}{l}\text { Leão, Real, Carrefour, Oetker, } \\
\text { LinTea, Littlemilla, Nobel, }\end{array}$ & 7 \\
\hline Condor Super Center $/ 2$ & $\begin{array}{l}\text { Leão, Real, Poliervas, Oetker, Lin } \\
\text { Tea, Prenda }\end{array}$ & 6 \\
\hline Extra/2 & Leão, Real, Oetker, Lin Tea, Castellari & 5 \\
\hline Supermercado Superpão/1 & Leão, Celeiro do Brasil, Prenda & 3 \\
\hline Benato Supermercados/1 & Leão, Real, Poliervas & 3 \\
\hline Supermercados Pão de Açucar/3 & Leão, Real. & 2 \\
\hline Supermercado Festival/4 & Leão, Chamel & 2 \\
\hline Lembrasul Supermercados/2 & Leão, Real, & 2 \\
\hline Stall Supermercados/1 & Leão, Real, & 2 \\
\hline Videira Supermercados $/ 1$ & Leão, Real, & 2 \\
\hline Supermercados Jacomar/1 & Leão, Real & 2 \\
\hline Supermercado Cilla/1 & Real & 1 \\
\hline
\end{tabular}

FONTE: Pesquisa de campo, 2001.

NOTA: As marcas comercializadas não estão disponíveis em todas as lojas de uma mesma rede.
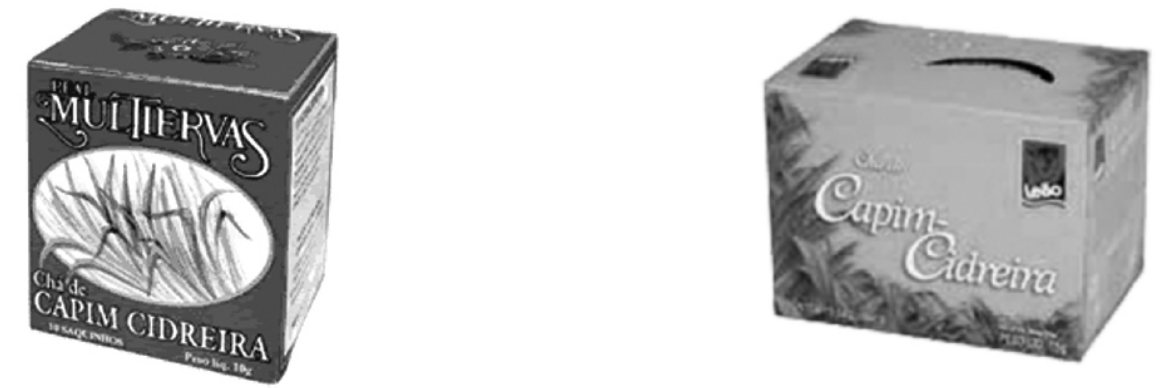

\section{FIGURA 3 - MARCAS DE CHÁ DE CAPIM-LIMÃO MAIS FREQÜENTES NOS SUPERMERCADOS DE CURITIBA}

As marcas rastreadas e identificadas apresentavam distintas procedências sendo 9 originárias do Paraná, 6 de São Paulo, 4 do Rio Grande do Sul e uma de Santa Catarina (Tabela 4). A identificação da origem, marca, nome ou razão social são consideradas informações obrigatórias, de acordo com a Portaria $n^{\circ} 42 / 98$ e RDC $n^{\circ}$ 259/02 (BRASIL, 1998 b; 2002 b). 


\section{TABELA 4 - IDENTIFICAÇÃO E ORIGEM DAS MARCAS DE CHÁ DE CAPIM-LIMÃO COMERCIALIZA DAS PELO SEGMENTO SUPERMERCADO EM CURITIBA - AGO-OUT 2001.}

\begin{tabular}{|l|l|l|l|}
\hline MARCA & ESTADO & CIDADE & EMPRESA \\
\hline Api.Chá & São Paulo & Campinas & ApiNutre \\
\hline BIG & Rio Grande do Sul & Porto Alegre & Madrugada \\
\hline Carrefour & Paraná & Curitiba & Moinhos Unidos \\
\hline Castellari & São Paulo & São Paulo & Linguanoto \\
\hline Celeiro do Brasil & Paraná & Cascavel & Celeiro do Brasil \\
\hline Chamel & Paraná & $\begin{array}{l}\text { Região Metropolitana de } \\
\text { Curitiba- Campo Largo }\end{array}$ & Chamel \\
\hline China Town & São Paulo & Baurú & Casa de Chá China Town \\
\hline Great Vallue & Paraná & Curitiba & Moinhos Unidos \\
\hline Leão & Paraná & Curitiba & Leão Júnior \\
\hline LinTea & São Paulo & São Paulo & LinTea \\
\hline Littlemilla & Rio Grande do Sul & Porto Alegre & Littlemilla \\
\hline Mercadorama & Rio Grande do Sul & Porto Alegre & Madrugada \\
\hline Nobel & Santa Catarina & Xanxerê & Nobelchás \\
\hline Oetker & São Paulo & São Paulo & Oetker \\
\hline Poliervas & Paraná & Curitiba & Poliervas \\
\hline Prenda & Rio Grande do Sul & Canoas & Prenda \\
\hline Produtos da Roça & Paraná & Guarapuava & Fundação Rureco/ Cercopa \\
\hline Real & Paraná & Curitiba & Moinhos Unidos \\
\hline Terra Ervas & Paraná & Curitiba & Terra Ervas \\
\hline TOTAL: 19 & Paraná, São Paulo, Rio Grande do Sul, Santa Catarina. \\
\hline
\end{tabular}

FONTE: Pesquisa de campo, 2001.

\subsubsection{FORMADE COMERCIALIZAÇÃO EACONDICIONAMENTO}

Em todos os estabelecimentos selecionados, o produto denominado "chá de capim-limão" comercializado referia-se ao alimento embalado, constituído de planta seca desidratada moída (68,4\% do total de marcas) ou fragmentada (31,6\%).

A planta seca desidratada moída, foi identificada em 8 marcas acondicionadas em sachês, organizados dentro de caixas de papel envoltas por filme plástico (embalagem secundária). Em 5 marcas, os saches eram adicionalmente embalados em envelope de papel (embalagem terciária) (Tabela 5). Quando se tratava de planta seca desidratada fragmentada, estava contida em embalagem primária, correspondendo a saco plástico transparente ( 5 marcas) ou pote plástico transparente com tampa (1 marca) (Tabela 5).

As formas de acondicionamento evidenciadas não ferem a legislação vigente. Entretanto, as embalagens secundárias e terciárias oferecem melhor proteção na medida que o risco de ruptura destas é bem menor, evitando a contaminação do produto disponível ao mercado consumidor.

\subsubsection{DENOMINAÇÃO DE VENDADO ALIMENTO OU NOME ESPECÍFICO}

O nome específico que caracteriza o alimento é fixado por regulamento técnico, no caso dos chás, pela Portaria n 519/98 (BRASIL,1998 a), que define os 
Padrões de Identidade e Qualidade. Este nome específico é chamado pela Portaria ${ }^{\circ}$ 42/98 e pela RDC n 259/02 de "denominação de venda do alimento". Esta é uma das informações obrigatórias exigidas por esta Resolução, que deve constar no painel principal do produto. Entretanto, no caso do capim-limão, a própria Portaria $n^{\circ}$. 519/98 apresenta incorreção na grafia do nome cientifico, que ao invés de Cymbopogon citratus (D.C.) Stapf, apresenta como nome científico Cymbopogon citratus Stapf, o que se configura numa incorreção na autoria desta espécie.

Também há que se considerar, na análise da grafia, os aspectos da nomenclatura botânica que estabelecem que nomes científico, por estarem em latim, devem estar em negrito ou itálico, sendo apenas a inicial do nome do gênero em letra maiúscula. Todo nome científico deve estar acompanhado do nome correto do autor da espécie, assim como deve refletir a história de alterações deste nome a partir de sua proposição.

Todas as marcas analisadas indicavam em seu rótulo a espécie vegetal Cymbopogon citratus como matéria prima de seu produto. Entretanto, em 9 marcas detectou-se incorreções ou omissões parciais na grafia do nome científico desta espécie (Tabela 5). Nestes casos, indica-se a adequação destas grafias de modo a minimizar quaisquer possibilidades de erro de identificação do material comercializado.

Estas diferentes marcas, também, apresentavam variação na indicação do nome popular da espécie em questão, sendo "capim-cidreira" o mais utilizado $(47,4 \%$ das marcas) seguida por "capim-limão"(26,3\%). Em 10\% das marcas, registrou-se a denominação "erva-cidreira", também empregada para outras espécies botânicas como Lippia alba (Mill.) N.E.Br. ex Britt \& Wilson e Melissa officinalis L.

\subsubsection{CONTEÚDO LÍQUIDO}

Em acordo ao estabelecido pelas Portaria $n^{\circ} 42 / 98$ e Resolução RDC $n^{\circ}$ 259/02, em todos os rótulos das marcas avaliadas registraram-se indicação do peso líquido sendo este bastante variável (valor mínimo $=10 \mathrm{~g}$; valor máximo $=150 \mathrm{~g}$, média = $19,7 \mathrm{~g}$ ), sendo mais freqüentemente registrados o peso de $10 \mathrm{~g}$, mesmo que as referidas legislações não definam um volume quantificável (Tabela 5).

\section{TABELA 5 - INFORMAÇÕES SOBRE AS MARCAS DE CHÁ DE CAPIM-LIMÃO COMERCIALIZADAS PELO SEGMENTO SUPERMERCADO NA CIDADE DE CURITIBA AGO-OUT. 2001.}

\begin{tabular}{|c|c|c|c|}
\hline MARCA & $\begin{array}{l}\text { GRAFIA DO NOME CIENTÍIICO-NOME POPULAR COMO } \\
\text { APRESENTADAS NOS RÓTULOS (INDICAÇÃO DO ERRO } \\
\text { OU OMISSÃO) }\end{array}$ & $\begin{array}{l}\text { TIPO DE } \\
\text { EMBALAGEM }\end{array}$ & $\begin{array}{l}\text { PESO } \\
\text { LÍQUIDO } \\
(g)\end{array}$ \\
\hline Leão & Cymbopogon citratus - Capim cidreira (falta autor) & Terciária & $10 ; 20$ \\
\hline Api.Chá & $\begin{array}{l}\text { Cymbopogon citratus Staph - Cidreira (autor escrito de forma } \\
\text { incompleta e incorreta, gênero e espécie em letra não itálico) }\end{array}$ & Terciária & 24 \\
\hline Castellari & Cymbopogon citratus - Erva cidreira -capim-limão(falta autor) & Terciária & 30 \\
\hline LinTea & $\begin{array}{l}\text { Cymbopogon citratus, Stapf - Capim cidreira (autor escrito } \\
\text { de forma incompleta, presença incorreta de virgula) }\end{array}$ & Terciária & 10 \\
\hline Oetker & $\begin{array}{l}\text { Cymbopogon citratus,S.- Cidreira (nome do autor incompleto, } \\
\text { presença incorreta de virgula) }\end{array}$ & Terciária & 15 \\
\hline Real & $\begin{array}{l}\text { Cymbopogon citratus - Cidreira (falta autor, gênero e espécie } \\
\text { em letra não itálico) }\end{array}$ & Secundária & \\
\hline
\end{tabular}




\begin{tabular}{|c|c|c|c|}
\hline Carrefour & $\begin{array}{l}\text { CYMBOPOGON CITRATUS - Cidreira (falta autor, falta, } \\
\text { gênero e espécie em letra maiúscula e não itálica) }\end{array}$ & Secundária & \\
\hline $\begin{array}{l}\text { Great } \\
\text { Vallue }\end{array}$ & Cymbopogon citratus - Cidreira (falta autor) & Secundária & 10 \\
\hline $\begin{array}{l}\text { Terra } \\
\text { Ervas }\end{array}$ & Cybopogon citratus- Cidreira (falta autor e letra no gênero) & Secundária & 10 \\
\hline BIG & Cymbopogon citratus- Capim cidreira (falta autor) & Secundária & 10 \\
\hline $\begin{array}{l}\text { Mercado- } \\
\text { rama }\end{array}$ & $\begin{array}{l}\text { Cymbopogon Citratus, Stapf - Capim cidreira (nome do autor } \\
\text { incompleto, gênero e espécie com letra inicial em maiúscula } \\
\text { e não itálico, presença incorreta de virgula) }\end{array}$ & Secundária & 10 \\
\hline Nobel & $\begin{array}{l}\text { Cymbopogon citratos,Stapf - Capim cidreira (nome do autor } \\
\text { incompleto, gênero e espécie em letra não itálico, espécie } \\
\text { escrita incorretamente, presença incorreta de virgula) }\end{array}$ & Secundária & 10 \\
\hline Prenda & $\begin{array}{l}\text { Cymbopogon citratus, Stapf - Capim cidreira(nome do autor } \\
\text { incompleto, presença incorreta de virgula) }\end{array}$ & Secundária & 10 \\
\hline Poliervas & $\begin{array}{l}\text { Cymbopogon Citratus - Capim-limão (falta autor, gênero e } \\
\text { espécie em letra maiúscula e não itálico) }\end{array}$ & $\begin{array}{c}\text { Primária } \\
\text { (pote plástico) }\end{array}$ & 15 \\
\hline Chamel & Cymbopogon citratus - Capim-limão (falta autor) & $\begin{array}{c}\text { Primária } \\
\text { (saco plástico) }\end{array}$ & 50 \\
\hline $\begin{array}{l}\text { Celeiro } \\
\text { do Brasil }\end{array}$ & Cymbopogon citratus - Capim-limão (falta autor) & $\begin{array}{l}\text { Primária } \\
\text { (saco plástico) }\end{array}$ & 30 \\
\hline $\begin{array}{l}\text { Produtos } \\
\text { da Roça }\end{array}$ & $\begin{array}{l}\text { Cymbopogon citratus - Capim-limão(falta autor, gênero e } \\
\text { espécie em letra não itálico) }\end{array}$ & $\begin{array}{c}\text { Primária } \\
\text { (saco plástico) }\end{array}$ & 50 \\
\hline Littlmilla & $\begin{array}{l}\text { Cymbopogum Citratus - Capim cidró (falta autor, gênero e } \\
\text { espécie em letra não itálico, gênero escrito incorretamente } \\
\text { espécie escrita com letra inicial maiúscula) }\end{array}$ & $\begin{array}{c}\text { Primária } \\
\text { (saco plástico.) }\end{array}$ & 50 \\
\hline $\begin{array}{l}\text { China } \\
\text { Town }\end{array}$ & Cymbopogon citratus - Erva cidreira (falta autor) & $\begin{array}{c}\text { Primária } \\
\text { (saco plástico) }\end{array}$ & 10 \\
\hline
\end{tabular}

FONTE: Pesquisa de campo, 2001.

A maioria das marcas analisadas de capim-limão apresentava correta indicação da parte utilizada, ou seja "folha", conforme estabelece a Portaria do Ministério da Saúde $n^{\circ} 519 / 98$. Contrariando a portaria citada, na rotulagem da marca Castellari foram identicados os dizeres : "folha e outras partes do ramo", como parte usada e na Poliervas ausência de indicação da parte a ser usada.

\subsubsection{ALEGAÇÃO DE EFEITO, PROPRIEDADE TERAPÊUTICAOU MEDICINAL}

Não foi registrado na rotulagem de nenhuma das marcas analisadas, alegações de efeitos, propriedades medicinais ou outras, atendendo assim a exigência da RDC $n^{\circ}$ 259/02 e sua antecessora a Portaria $n^{\circ} 42 / 98$ e a Portaria n 519/98 (BRASIL, 1998 a;1998 b; 2002 b). Pela legislação brasileira, chá é considerado alimento e não medicamento e como tal não é pemitido que conste na rotulagem tais informações. Porém, em pesquisa nos sites de algumas empresas responsáveis pelas marcas, constavam tais informações na propaganda dos produtos, visto não haver legislação que proiba tal procedimento.

\subsubsection{OUTROS ÍTENSDO RÓTULO}

Todas as marcas avaliadas estavam de acordo com as exigências da Portaria $\mathrm{n}^{\circ}$ $42 / 98$ e RDC $n^{\circ}$ 259/02, no que se refere às informações referentes à lista de 
Ingredientes, nome ou razão social, identificação do lote, prazo de validade, instruções sobre o preparo e uso do alimento, quando necessário.

\subsection{ROTULAGEM NUTRICIONAL DO CHÁ DE CAPIM-LIMÃO}

Seis das nove marcas analisadas não apresentavam rotulagem nutricional conforme estabelecido pelas RDC $n^{\circ} 39 / 01$ e RDC n 40/01, quando da avaliação procedida em 2001 em período precedente ao prazo final de adequação à esta legislação (BRASIL, 2002 a; 2003 a). As principais falhas registradas, nesta oportunidade, foram ausência da declaração obrigatória de valor calórico, nutrientes e componentes. Em posterior avaliação, realizada em maio de 2003 , verificou-se que cinco das nove marcas haviam se adequado à legislação vigente incorporando a rotulagem nutricional em suas embalagens.

\subsection{USO DE IRRADIAÇÃO OU PROCESSO ANÁLOGO}

A Resolução da ANVISA, RDC $n^{\circ} 21 / 01$, que estabelece o regulamento técnico para irradiação de alimentos, exige dentre os requisitos obrigatórios que na rotulagem dos alimentos irradiados, deva constar no painel principal do rótulo do produto, em letras maiúsculas e de tamanho não inferior a $1 / 3$ do da letra de maior tamanho nos dizeres da rotulagem: ALIMENTO TRATADO POR PROCESSO DE IRRADIAÇÃO. Esta informação deve constar também nas notas fiscais e nos locais de exposição à venda, por meio de cartaz.

Em nenhuma das marcas avaliadas foi registrada a indicação no rótulo de utilização de irradiação durante o processo produtivo ou beneficiamento do produto. A informação de ausência do emprego da irradiação foi confirmada junto aos técnicos das indústrias, por via telefônica. Desta forma, todas as marcas se adequam ao preconizado na legislação vigente.

\subsection{PRODUÇÃO ORGÂNICADE CHÁ DE CAPIM-LIMÃO}

Apenas uma das marcas avaliadas (Produtos da Roça) foi identificada como oriunda de produção orgânica, a partir das informação do rótulo. Esta marca também foi a única a apresentar selo de certificação conferido pela Associação de Estudos, Orientação e Assistência Técnica Rural ASSESSOAR. As demais marcas são obtidas através de cultivo tradicional sem certificação orgânica.

No Brasil é proibido o uso de agroquímicos na produção de plantas medicinais, como o capim-limão, porque estes produtos além de gerarem danos ao meio ambiente e a saúde e segurança alimentar do consumidor, não são registrados em organismos oficiais brasileiros para tal finalidade (MONTANARI JÚNIOR, 2000/2001; BRASIL, $2003 b$ ). Entretanto, visitas e entrevistas a produtores levam a crer que esta é prática que, eventualmente, pode ser empregada no cultivo do capim-limão.

\section{CONSIDERAÇÕES FINAIS E RECOMENDAÇÕES}

Os indicadores nominados na rotulagem das marcas analisadas de capim- 
Limão, demonstram a conscientização efetiva do segmento agroindustrial da cadeia produtiva do capim-limão, quanto ao cumprimento da legislação vigente no que concerne a quase totalidade dos parâmetros considerados. Entretanto, a incorreção mais freqüente refere-se a denominação de venda ou nome específico.

Com vistas a saúde e segurança alimentar do consumidor, recomenda-se aos agroindustriais a qualificação constante do chá de capim-limão, por meio de:

4.1. Acondicionamento: priorização ao uso de embalagens secundárias ou terciárias, para maior proteção do alimento;

4.2. Rotulagem - no quesito denominação de venda ou nome específico: adoção do nome científico correto da espécie, acompanhado de autoria, ou seja: Cymbopogon citratus (D.C.) Stapf.

4.3. Inserção da rotulagem nutricional, em forma de tabela, incluindo o valor calórico, seguido da declaração de nutrientes e componentes básicos, na seguinte ordem: carboidratos, proteínas, gorduras totais e sódio.

Também, dado que o chá de capim-limão é freqüentemente utilizado como planta medicinal, além de complemento alimentar, recomenda-se aos produtores agrícolas a adoção de práticas agronômicas corretas do ponto de vista ecológico e/ou tradicional sob orientação de profissional técnico. Aos agroindustriais, comerciantes e aos consumidores, recomenda-se a prática da exigência de produto de qualidade.

Especificamente à ANVISA, sugere-se correção da Portaria $n^{\circ}$ 519/98 no que concerne à grafia do nome específico do capim-limão: Cymbopogon citratus (D.C.) Stapf.

\section{REFERÊNCIAS}

AKISUE, G.;AKISUE, M. K.; SILVA, J. R. ;ANDALUZ, M. I. Padronização da droga e do extrato fluido de Cymbopogon citratus (D.C.) Stapf. Lecta, Bragança Paulista, v. 14, n. 2, p. 109-119, 1996.

ABRAS. ASSOCIAÇÃO BRASILEIRA DE SUPERMERCADOS. Ranking Abras Edição 2000. Superhiper, São Paulo, v. 26, p. 26-29, 70, 82-94, 123, 2000.

APRAS. ASSOCIAÇÃO PARANAENSE DE SUPERMERCADOS. Consumo ainda está sob controle. Supermix, Curitiba, n. 47, p. 50-54, 1999.

APRAS. ASSOCIAÇÃO PARANAENSE DE SUPERMERCADOS. Supermercados

refletem diversidade. Supermix, Curitiba, n. 61, p. 16-18, 2000.

APRAS. ASSOCIAÇÃO PARANAENSE DE SUPERMERCADOS. A rota da qualidade.

Supermix, Curitiba, n. 65, p. 26-30, 2001.

BENDER, A. E. Dicionário de nutrição e tecnologia de alimentos. Tradução:. A Neves; R. Sirota; R. S., Azevedo Neto, 4. ed. São Paulo: Roca, 1982, 212 p.

BRASIL. Ministério da Agricultura, Pecuária e Abastecimento. Legislação

Fitossanitária. Disponível em: < http //www.agricultura.gov.br> Acesso em: 17 mar. 2003b.

BRASIL. Ministério da Saúde. Agência Nacional de Vigilância Sanitária. Resolução RDC daANVISAn. 21 de 26 de janeiro de 2001. Regulamento técnico para irradiação De alimentos. Diário Oficial da União, Brasília, DF, 29 jan. 2001 a.

BRASIL. Ministério da Saúde. Agência Nacional de Vigilância Sanitária. ResoluçãoRDC da ANVISA n. 39 de 21 de março de 2001. Tabela de valores de referência para porções de alimentos e bebidas embalados para fins de rotulagem nutricional. Diário Oficial da União, Brasília, DF, 22 mar. 2001 b. 
BRASIL. Ministério da Saúde. Agência Nacional de Vigilância Sanitária. Resolução RDC da ANVISAn. 40 de 21 de março de 2001. Rotulagem nutricional obrigatória de alimentos e bebidas embalados. Diário Oficial da União, Brasília, DF, 22 mar. 2001 c. BRASIL. Ministério da Saúde. Agência Nacional de Vigilância Sanitária. Resolução RDC da ANVISA n. 155 de 27 de maio de 2002. Prazo para a adequação da rotulagem nutricional. Diário Oficial da União, Brasília, DF, 29 maio 2002

BRASIL. Ministério da Saúde. Agência Nacional de Vigilância Sanitária. ResoluçãoRDC da ANVISAn. 259 de 20 de setembro de 2002. Regulamento técnico para rotulagem de alimentos embalados. Diário Oficial da União, Brasília, DF, 23 set. 2002.

BRASIL. Ministério da Saúde. Agência Nacional de Vigilância Sanitária. Notícias da Anvisa: Diário e Mensal. Rótulos de alimentos embalados devem cumprir regulamento da ANVISA até 20 de março. Disponível em: <http// www.anvisa.gov.br>.Acesso em: 13 mar. 2003a.

BRASIL. Ministério da Saúde. Secretaria de Vigilância Sanitária. Portaria da SVS n. 1428 de 26 de novembro de 1993. Regulamento técnico para inspeção sanitária de alimentos. Diário Oficial da União, Brasília, DF, 02 dez. 1993.

BRASIL. Ministério da Saúde. Secretaria de Vigilância Sanitária. Portaria da SVS n. 519 de 26 de junho de 1998. Regulamentos técnicos para fixação de identidade e qualidade de chás plantas destinadas à preparação de infusões ou decocções. Diário Oficial da União, Brasília, DF, 29 jun.1998 a.

BRASIL. Ministério da Saúde. Secretaria Nacional de Vigilância Sanitária. Portaria da SVS n. 42 de 14 de janeiro de 1998. Regulamento técnico referente à rotulagem de alimentos embalados. Diário Oficial da União, Brasília, DF, jan. 1998 b.

CURITIBA. Disponível em: <http://www.curitiba.pr.gov.br/pmc/curitiba/bairros $>$.Acesso em: 22 ago. 2001 a.

CURITIBA. Prefeitura Municipal de Curitiba. Instituto de Pesquisa e Planejamento Urbano de Curitiba. IPPUC. Curitiba em números. Curitiba: IPPUC, 2001b. 66 p.

FARMACOLOGIA pré-clínica e toxicologia do capim-cidrão, Cymbopogon citratus.

Brasília: CEME, 1985.52 p.

LEITE , J. R.; SEABRA, M.L. V.; MALUF, E. ; ASSOLANT, K.; SUCHEKI, D.; TUFIK, S.; KLEPACZ, S.; CALIL, H. M.; CARLINI, E. A. Pharmacology of lemon grass

(Cymbopogon citratus Stapf) III. Assessment of eventual toxic, hypnotic and ansiolytic effects on humans. Journal of Ethnopharmacology, Lausanne, v. 17, p. 75-83, 1986.

MONTANARI JÚNIOR, I. Aspectos legais da produção comercial de plantas medicinais. Agroecologia, Botucatu, n. 6, p. 25-26, 2000/2001.

OLIVEROS-BELARDO, L.; AUREUS, E. Essential oil from Cymbopogon citratus (D.C.) Stapf growing wild in the Philipines. In: INTERNATIONAL CONGRESS OF ESSENTIAL OILS, 7 th. ,1977, Manila. Anais...Manila: 1979. p.166-168.

PARANÁ. Secretaria de Estado da Agricultura e do Abastecimento-SEAB.

Departamento de Economia Rural. Divisão de Estatísticas Básicas. Levantamento do valor bruto da produção agropecuária: especiarias: safra 1999/2000. Curitiba, 2001. PARANÁ. Secretaria de Estado da Agricultura e do Abastecimento-SEAB. Departamento de Economia Rural. Divisão de Estatísticas Básicas. Levantamento do valor bruto da produção agropecuária: especiarias: safra 2000/2001. Curitiba, 2002. PARANÁ. Secretaria de Estado da Agricultura e do Abastecimento-SEAB.

Departamento de Economia Rural. Divisão de Estatísticas Básicas. Levantamento do valor bruto da produção agropecuária: especiarias: safra 2002 /2003. Curitiba, 2004 
PARANÁ. Secretaria Especial de Assuntos Estratégicos. Companhia de Informática do Estado do Paraná- CELEPAR. Dados cadastrais de empresas de beneficiamento de chá, mate e outras ervas para infusão/ beneficiamento, moagem e preparação de outros alimentos de origem vegetal. Disponível em:

http://www.celepar7.pr.gov.br/produserv/consulta. Acesso em: jan. 2003.

RABHA, L. C.; BARUAH, A. K. S.; BORDOLOI, D. N. Search for aroma chemicals of commercial value from plant resources of North East India. Indian Perfumer, v. 23, n. 3/4, p. 178-183, 1979.

RIEDEL, G. Controle sanitário dos alimentos. 2. ed. São Paulo: Atheneu, 1992. 320 p.

SILVAV. A.; FREITAS, J. C.; MATTOS, A. P. ; PRESGRAVE, O. E.; PAIVA, W.G.;

FINGOLA, F. F. ; MENEZES, M. A . ; PAUMGARTTEN, F. J. Neurobehavioral study of the effect of beta myrcene on rodents. Brazilian Journal of Medical and Biological Research, Ribeirão Preto, v. 24, n. 8, p. 827-831, 1991.

TESKE, M.; TRENTINI, M. M. Herbarium compêndio de fitoterapia. 3.ed. Curitiba: Herbarium. 1997. 317 p.

TORRES, R. S. Citral from Cymbopogon citratus (D.C.) Stapf (lemon grass) oil.

Phillipine Journal of Science, Manila, v. 122, n. 3, p. 269-287, 1993.

\section{AGRADECIMENTOS}

Aos funcionários da APRAS-Associação Paranaense de Supermercados e do IPPUCInstituto de Pesquisa e Planejamento Urbano de Curitiba, localizados em Curitiba, pelas informações e documentos disponibilizados. À bibliotecária do Campus III da Universidade Federal do Paraná, Sra. Liane dos Anjos, pela revisão nas referências deste trabalho. 